\title{
Loss-of-function myostatin mutation increases insulin sensitivity and browning of white fat in Meishan pigs
}

\author{
Chunbo Cai ${ }^{1,2}$, Lili Qian ${ }^{1,2}$, Shengwang Jiang ${ }^{1}$, Youde Sun ${ }^{4}$, Qingqing Wang ${ }^{1}$, Dezun \\ $\mathrm{Ma}^{1}$, Gaojun $\mathrm{Xiao}^{1}$, Biao $\mathrm{Li}^{1}$, Shanshan $\mathrm{Xie}^{1}$, Ting $\mathrm{Gao}^{1,3}$, Yaoxing Chen ${ }^{3}$, Jie Liư ${ }^{5}$, \\ Xiaorong An ${ }^{2}$, Wentao Cui ${ }^{1}$, Kui Li ${ }^{1}$ \\ ${ }^{1}$ Institute of Animal Sciences, Chinese Academy of Agricultural Sciences, Beijing, 100193, P. R. China \\ ${ }^{2}$ State Key Laboratory of Agro Biotechnology, China Agricultural University, Beijing, 100193, P. R. China \\ ${ }^{3}$ College of Animal Medicine, China Agricultural University, Beijing, 100193, P. R. China \\ ${ }^{4}$ Institute of Animal Sciences, Qingdao, 266100, P. R. China \\ ${ }^{5}$ Department of Bioengineering and Biotechnology, College of Chemical Engineering, Qingdao University of Science and \\ Technology, Qingdao, 266042, P. R. China
}

Correspondence to: Wentao Cui, email: cuiwentao@caas.cn

Kui Li, email: likui@caas.cn

Keywords: myostatin deficiency, skeletal muscle, fat, insulin sensitivity, irisin

Received: December 01, 2016

Accepted: March 22, 2017

Published: April 04, 2017

Copyright: Cai et al. This is an open-access article distributed under the terms of the Creative Commons Attribution License (CC-BY), which permits unrestricted use, distribution, and reproduction in any medium, provided the original author and source are credited.

\section{ABSTRACT}

Myostatin-deficient mice showed a remarkable hypertrophy of skeletal muscle, with a decreased fat mass and enhanced insulin sensitivity. Currently, it is unclear if the inhibition of myostatin could be used as an approach to treat human obesity and insulin resistance. In this study, we investigated if the inhibition of porcine myostatin has any effect on fat deposition and insulin sensitivity using genetically engineered Meishan pigs containing a myostatin loss-of-function mutation (Mstn ${ }^{-/-}$). Our results indicated that, when compared with wild-type pigs, the amount of subcutaneous fat and leaf fat of Mstn ${ }^{-/-}$pigs were significantly decreased mainly due to the browning of subcutaneous adipose tissue. Additionally, the serum insulin level decreased and the insulin sensitivity increased significantly in Mstn ${ }^{-/-}$pigs. Moreover, we found a significant increase in levels of insulin receptor and insulin receptor substrate proteins in skeletal muscle of Mstn ${ }^{-/-}$pigs, which then activating the insulin signaling pathway. Irisin-mediated regulation is not the only pathway for the activation of insulin signal in Mstn ${ }^{-/-}$skeletal muscle. This study provides valuable insight for the treatment of human obesity and diabetes mellitus.

\section{INTRODUCTION}

Myostatin is a transcriptional growth factor, also known as growth/differentiation factor 8 (GDF8), which is a member of the transforming growth factor beta (TGF $\beta$ ) superfamily. Myostatin is expressed mainly in skeletal muscle [1], and a small amount can be detected in fat, brain, heart, liver, and kidney [2, 3]. The main function of myostatin is its negative regulation of skeletal muscle growth and development [4]. Mstn ${ }^{-/}$mice have a remarkable increase in skeletal muscle mass and a significant decrease in fat mass when compared with their corresponding wild-type littermates [1]. It has been well established that natural mutations in myostatin can lead to skeletal muscle hypertrophy in species such as cattle $[5,6]$.
Therefore, myostatin becomes an important target for improving lean meat production in livestock production.

In addition to regulating the growth and development of skeletal muscle, myostatin also plays a regulatory role in fat deposition. It has been observed that myostatin expression in skeletal muscle and adipose tissue is significantly higher in obese mice and obese patients than in normal mice and healthy humans [7-9]. In transgenic myostatin propeptide mice where myostatin activity is inhibited, food-induced obesity was significantly reduced [10]. $\mathrm{Mstn}^{-/-}$mice had a reduced fat deposition compared with wild-type mice, and this phenotype was particularly pronounced with aging [11-13]. The main reason for the decrease in fat deposition in $\mathrm{Mstn}^{-/-}$mice is due to the increased browning of the white adipose 
tissue $[14,15]$. The expression of browning marker genes, such as uncoupling protein 1 (UCP1), peroxisome proliferative activated receptor, gamma, coactivator 1 alpha (PGC-1 $\alpha$ ), PR domain containing 16 (PRDM16), cell death-inducing DNA fragmentation factor, alpha subunit-like effector A (Cidea), tumor necrosis factor receptor superfamily member 9 (CD137), transmembrane protein 26 (Tmem26), was significantly increased in the white fat of $\mathrm{Mstn}^{-/-}$mice, which subsequently leads to fat consumption $[14,15]$. It is thus highly possible that the inhibition of myostatin activity can be used as a new strategy to treat obesity.

Recently, a number of studies have demonstrated that myostatin can also regulate the body's insulin sensitivity in mice. Insulin resistance has been known as one of the key cause for type 2 diabetes, so enhancing the insulin sensitivity could be an effective method to treat type 2 diabetes [16-18]. Compared with normal mice, the expression of myostatin in skeletal muscle increased significantly in diabetic mice [19, 20]. Very interestingly, the same phenomena were also observed in diabetic patients [21, 22]. Inhibition of myostatin activity by myostatin propeptide significantly attenuated insulin resistance in mice fed with a high-fat diet [10, 19]. The insulin sensitivity increased significantly in $\mathrm{Mstn}^{-/}$mice fed with either normal or high-fat diet [13, $20,23]$. Up to date, the regulatory mechanism of the insulin sensitivity by myostatin remains unclear. Bonala et al. [8] reported that myostatin can promote insulin receptor substrate 1 (IRS1) protein degradation, and thus weakening the activation of insulin signaling pathways, and subsequently resulting in insulin resistance. Dong et al. [24] reported that myostatin inhibition can reduce the expression of proinflammatory factors in adipose tissue, thus enhancing the insulin sensitivity in mice. It is evident that more investigation is required to study the molecular mechanism by which myostatin inhibition regulates the insulin sensitivity in vivo.

Currently, most functional studies on myostatin are mainly focused on small animals like mice with very little effort being made to use large mammals such as pigs. Pigs are the closest species similar to humans [25] and can thus be used as an ideal experimental animal model in the research and development of therapeutics to treat human diseases. Recently, our lab had successfully produced myostatin-deficient $\left(\mathrm{Mstn}^{-/-}\right)$Meishan pigs by using ZFN editing technology [26]. In this study, we investigated the effect of loss-of-function myostatin mutation on fat deposition and insulin sensitivity in pigs. Our findings demonstrate that, for the first time, the in vivo inhibition of myostatin activity resulted in significant increases in both insulin sensitivity and fat consumption in $\mathrm{Mstn}^{-/-}$Meishan pigs, and thus provide very useful insight into the use of myostatin inhibitors as an effective alternative approach to treat obesity and type 2 diabetics.

\section{RESULTS}

\section{An increase in skeletal muscle mass in $\mathrm{Mstn}^{-/}$ Meishan pigs}

Our lab has recently successfully generated Mstn -/- Meishan pigs by ZFN-editing technology [26]. In this study, the effect of myostatin deficiency on skeletal muscle and fat was further investigated at ages of 4 months and 16 months, respectively. Mstn ${ }^{-/-}$and wild-type Meishan pigs, fed with standard diet, were slaughtered at 4 months and 16 months, respectively. There was no significant difference in body weight between $\mathrm{Mstn}^{-/}$and wildtype Meishan pigs at 4 months (Figure 1A). However, the relative mass (expressed as \% of body weight) of longissimus dorsi, semitendinosus, semimembranosus and triceps all increased significantly in $\mathrm{Mstn}^{-/}$Meishan pigs compared to wild-type pigs (Figure 1B). At 16 months of age, when pigs' growth matured, the body weight of Mstn $^{-/-}$Meishan pigs was significantly heavier than that of the wild-type pigs (Figure 1C), and the percentage of skeletal muscle mass from $\mathrm{Mstn}^{-/-}$Meishan pigs increased significantly (46.51\% for $\mathrm{Mstn}^{-/}$pigs vs $35.34 \%$ for wildtype pigs, see Figure 1D), an increase of $11.17 \%$. Similarly, the percentages of longissimus dorsi, semitendinosus, semimembranosus and triceps of $\mathrm{Mstn}^{-1-}$ Meishan pigs were also significantly higher than in the wild-type pigs (Figure 1E). We also isolated the longissimus dorsi muscle from 16-month-old Meishan pigs and measured their loin eye areas of carcass, and found that $\mathrm{Mstn}^{-1-}$ Meishan pigs had much higher loin eye areas than wild-type pigs (Figure 1F and 1G). Our results show that skeletal muscle mass in $\mathrm{Mstn}^{-1-}$ Meishan pigs increased significantly at 4 months of age and was maintained the higher level up to the adulthood age (16 months).

\section{A decrease in fat mass in $\mathrm{Mstn}^{-1-}$ Meishan pigs}

The excessive accumulation of white fat is the main cause of obesity, which is a serious threat to human health. The effect of myostatin deletion on fat deposition was examined in $\mathrm{Mstn}^{-1-}$ Meishan pigs. Result in Figure 2A showed that the relative percentage of subcutaneous fat mass to body weight in $\mathrm{Mstn}^{-1-}$ Meishan pigs is $5.324 \%$, significantly lower than in wild-type pigs, whose value is $8.572 \%$, a $3.248 \%$ decrease at the age of 16 months. Backfat thickness is an important index to measure subcutaneous fat deposition. Compared to wild-type pigs, $\mathrm{Mstn}^{-/}$Meishan pigs have a significant reduction in backfat thickness (Figure 1F and Figure 2B). Additionally, the mass of leaf fat also decreased significantly in Mstn ${ }^{-/}$Meishan pigs $\left(1.152 \%\right.$ in $\mathrm{Mstn}^{-/}$pigs vs $2.697 \%$ in wild-type pigs), a $1.382 \%$ drop (Figure 2C-2D). Serum leptin and triglyceride levels are known to be associated with body fat deposition $[27,28]$. We measured leptin and 
triglyceride levels in serum from 4M and 16M Meishan pigs (Figure 2E-2F), and observed no significant changes in serum leptin and triglyceride levels at 4 months between wild-type and $\mathrm{Mstn}^{-1-}$ Meishan pigs. However, serum leptin and triglyceride levels in the 16-month-old Mstn
${ }^{-/}$Meishan pigs decreased significantly (Figure 2E-2F). Further, our data show that the relative percentage of white fat and leaf fat, along with serum leptin and triglyceride levels, are all significantly reduced in adult $\mathrm{Mstn}^{-/}$pigs compared to wild-type pigs.
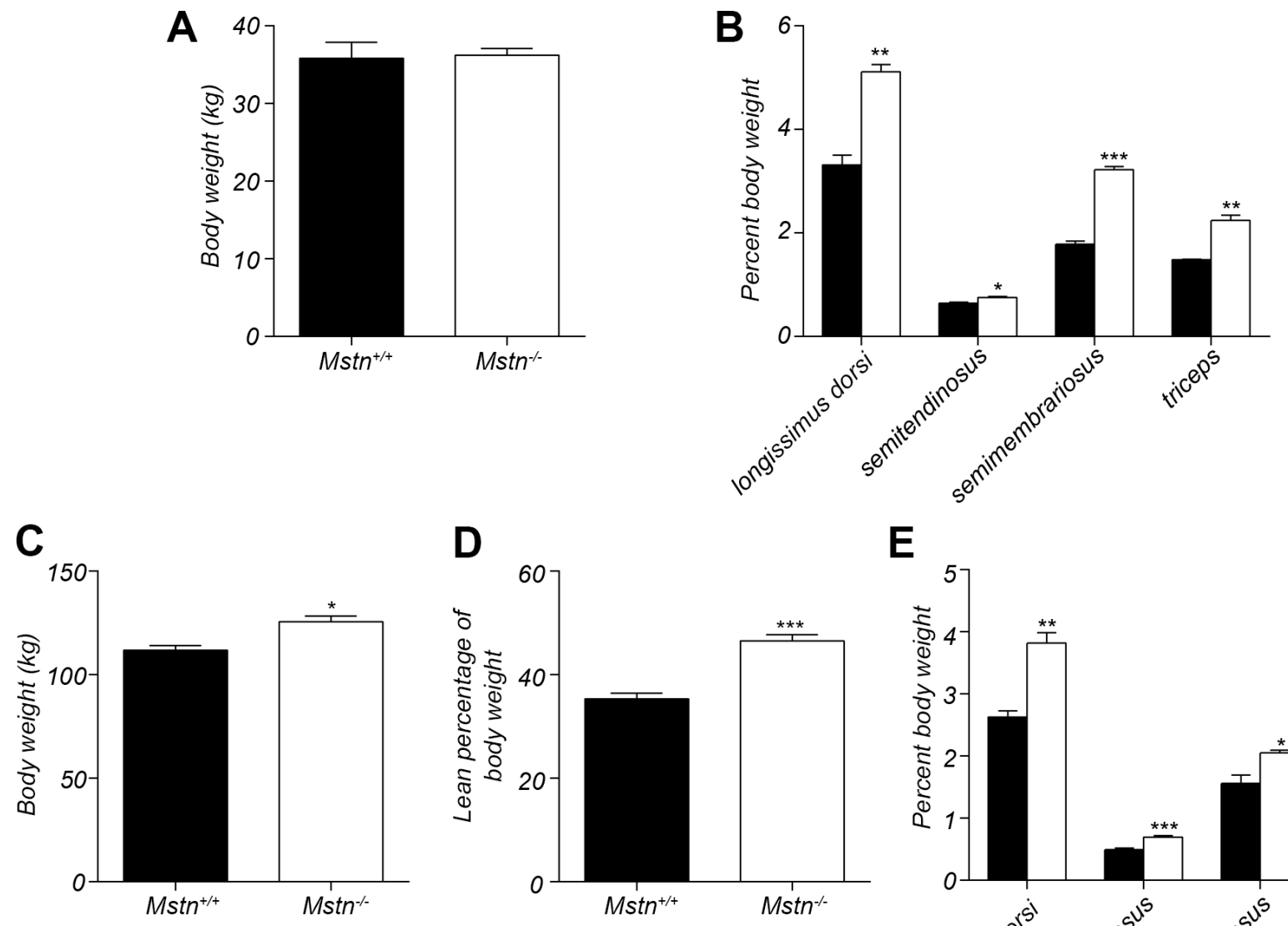

E

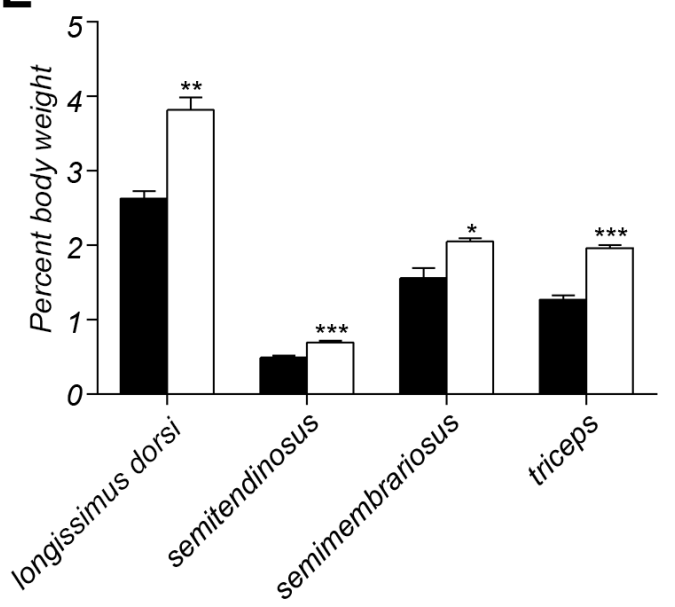

F

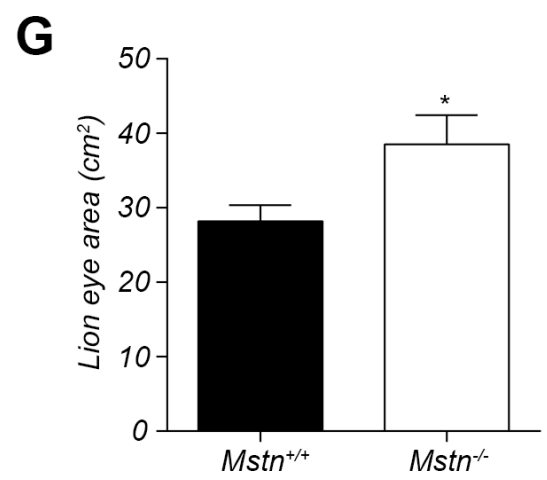

Figure 1: Changes in body weight and relative skeletal muscle mass. (A) Body weight (mean \pm SEM, $n=4$ pigs) of 4-month old pigs. (B) Percent longissimus dorsi, semitendinosus, semimembranosus, and triceps of body weight for 4-month old pigs. Data are reported as mean $\pm \operatorname{SEM}(n=4)$. ${ }^{*} P<0.05$, ${ }^{*} P P<0.01, * * * P<0.001$. (C) Body weight (mean \pm SEM, $n=4$ pigs) of 16 -month old pigs. $* P<0.05,{ }^{*} P<0.01,{ }^{*} * P<0.001$. (D) Percent skeletal muscle of body weight for 16-month old pigs. Data are reported as mean \pm SEM $(n=4) . * P<0.05, * * P<0.01,{ }^{*} * * P<0.001$. (E) Percent longissimus dorsi, semitendinosus, semimembranosus, and triceps of body weight of 4-month old pigs. Data are reported as mean $\pm \operatorname{SEM}(n=4)$. $* P<0.05, * * P<0.01, * * * P<0.001$. (F) The cross section of longissimus dorsi and subcutaneous fat between 6 th and 7 th ribs in 16-month old pigs. (G) The lion eye area (mean \pm SEM, $n=4$ pigs) of longissimus dorsi between the 6th and 7th ribs. ${ }^{*} P<0.05, * * P<0.01, * * * P<0.001$. Black bar: Mstn $^{+/+}$(wild-type) pigs; white bar: Mstn ${ }^{-/-}$pigs. 


\section{Increased browning of subcutaneous fat in Mstn ${ }^{-/}$Meishan pigs}

The molecular mechanism by which fat in $\mathrm{Mstn}^{-/}$ mice is reduced is mainly due to the browning of white fat, which leads to an increase in fat consumption [14]. We explored the molecular mechanism of fat decrease in $\mathrm{Mstn}^{-/-}$Meishan pigs. HE staining results indicated that the lipid droplets in the subcutaneous adipose tissue of $M s n^{-1}$ Meishan pigs are smaller than in wild-type pigs (Figure 3A). The family of uncoupling protein has an important role in fat consumption. There is no significant change in the expression of UCP2 but a significant increase in the expression of UCP3 in $\mathrm{Mstn}^{-/-}$Meishan pigs (Figure 3B). Western blot analysis showed that UCP3 protein level increased significantly in backfat of $\mathrm{Mstn}^{-1-}$ Meishan pigs compared with the wild-type pigs (Figure 3E). Further immunohistochemistry indicated that the UCP3 level in the subcutaneous adipocyte interstitial space of $\mathrm{Mstn}^{-/-}$Meishan pigs increased significantly (Figure 3C). Expression results of browning marker genes in subcutaneous adipose tissue showed that the expression of PGC-1 $\alpha$, PRDM16 and Cidea in Mstn $^{-/-}$Meishan pig was significantly higher (Figure 3D). The protein level of PGC-1 $\alpha$ in the subcutaneous fat of $\mathrm{Mstn}^{-/-}$Meishan pigs also increased significantly as seen in WB (Figure 3E). The expression of CD137 and Tmem26, two marker genes of beige fat, in the subcutaneous fat of $\mathrm{Mstn}^{-/-}$Meishan pigs was also elevated (Figure 3F). Our results suggested an increased browning of white fat in $\mathrm{Mstn}^{-/-}$Meishan pigs.

\section{Increase in insulin sensitivity induced by myostatin deletion}

It has been reported that insulin sensitivity increased significantly in $\mathrm{Mstn}^{-/-}$mice compared to wild-type mice $[13,19]$. However, no study has been conducted on the relationship between myostatin and insulin sensitivity in large mammals. In this study, we investigated the changes in insulin sensitivity in $\mathrm{Mstn}^{-1-}$ Meishan pigs compared to wild-type pigs. At 4 months of age, although there is no significant difference in serum glucose level between $M_{s t n}{ }^{-/}$Meishan pigs and wild-type pigs (Figure 4A), serum insulin level was significantly lower in Mstn
A

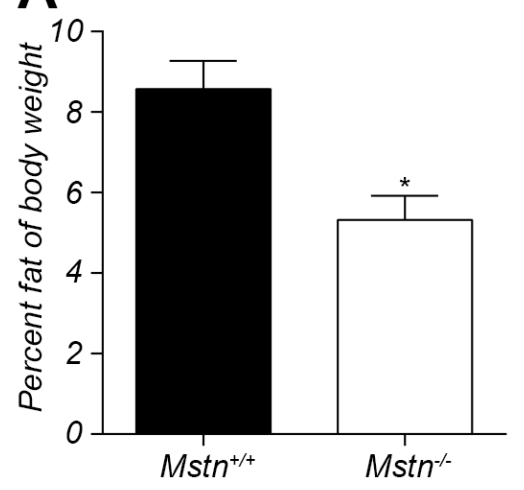

D

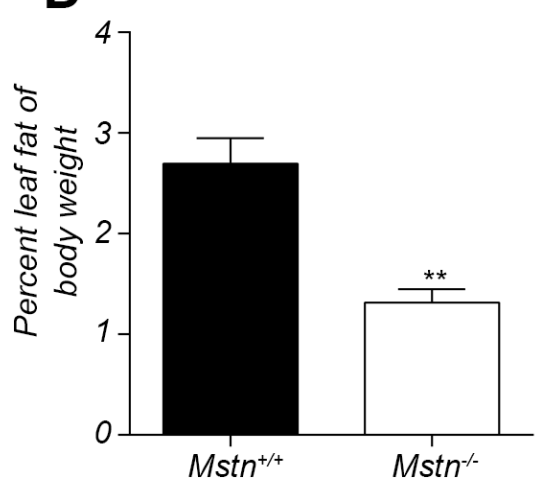

B



E

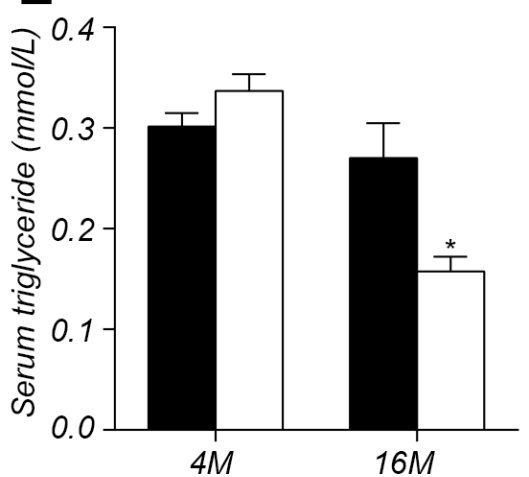

C

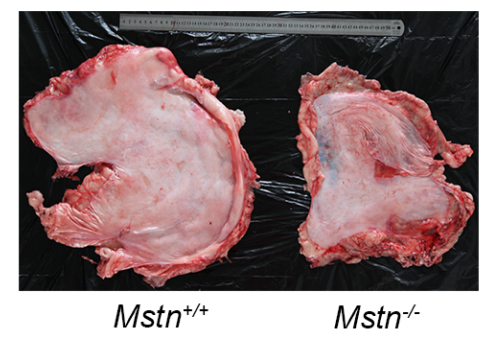

$\mathbf{F}$

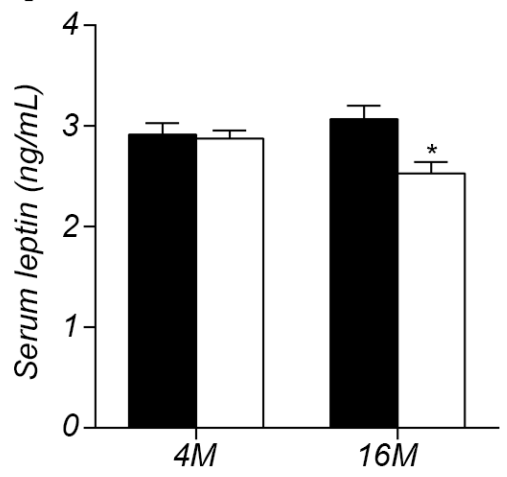

Figure 2: Changes in fat mass and serum levels of triglyceride and leptin. (A) Percent subcutaneous fat of body weight for 16 -month old pigs. Data are reported as mean $\pm \operatorname{SEM}(n=4)$. $* P<0.05, * * P<0.01, * * * P<0.001$. (B) thickness of backfat between 6th and 7 th ribs from 16-month old pigs. Data are reported as mean $\pm \operatorname{SEM}(n=4)$. $* P<0.05, * * P<0.01, * * * P<0.001$. (C) Photos showing leaf fat from 16-month-old wild-type and $\mathrm{Mstn}^{-/-}$Meishan pigs. (D) Percent leaf fat of body weight for 16-month old pigs. Data are reported as mean $\pm \operatorname{SEM}(n=4)$. $* P<0.05,{ }^{*} P<<0.01, * * * P<0.001$. (E) Serum level of triglyceride in 4-month old and 16-month old pigs. Data are reported as mean $\pm \operatorname{SEM}(n=4) . * P<0.05, * * P<0.01, * * * P<0.001$. (F) Serum level of leptin in 4-month old and 16-month old pigs. Data are reported as mean $\pm \operatorname{SEM}(n=4) .{ }^{*} P<0.05, * * P<0.01, * * P<0.001$. Black bar: Mstn $^{+/+}$(wild-type); pigs white bar: $M s t n^{-/}$pigs. 
Meishan pigs than in wild-type pigs (Figure 4B). The insulin sensitivity index is much greater in $\mathrm{Mstn}^{-/}$ Meishan pigs than in wild-type pigs (Figure 4D). We also performed insulin immunohistochemistry in pancreatic tissue and found that insulin secretion was reduced in Mstn

${ }^{-/}$Meishan pigs compared to wild-type pigs (Figure 4C), which is consistent with the reduced level of serum insulin in $\mathrm{Mstn}^{-1-}$ Meishan pigs. Similarly, at 16 months of age, serum insulin level was also significantly decreased in Mstn ${ }^{--}$Meishan pigs (Figure 4B), and the insulin sensitivity increased significantly (Figure 4D). We then performed a glucose tolerance test in 4 month-old Meishan pigs (Figure 4E). The result showed that $\mathrm{Mstn}^{-/}$Meishan pigs had better glucose tolerance compared to the wild-type pigs. The values of area under curve (AUC) (Figure 4F) were significantly lower in $\mathrm{Mstn}^{-/-}$Meishan pigs compared to the wild-type pigs. All of these data indicate that the insulin sensitivity increased significantly in $\mathrm{Mstn}^{-/-}$Meishan pigs.

\section{Activation of insulin signaling pathway in skeletal muscle of $\mathrm{Mstn}^{-/-}$Meishan pigs}

Since skeletal muscle is the main site of glucose metabolism, we investigated the changes of insulin signal pathway in longissimus dorsi. The expression of InsR and IRS1, two key proteins in the insulin signaling pathway, had no significant difference in longissimus dorsi muscle between $\mathrm{Mstn}^{-1-}$ Meishan pigs and the wild-type pigs (Figure 5A). However, the protein levels of InsR and IRS1 in $\mathrm{Mstn}^{-/-}$Meishan longissimus dorsi muscle were significantly greater than that in the wildtype pigs (Figure 5B). Additionally, the phosphorylated InsR (p-InsR) and IRS1 (p-IRS1) were also significantly increased in $\mathrm{Mstn}^{-1}$ pigs (Figure 5B). The downstream proteins of the insulin signaling pathway, Akt, p-Akt and GLUT4, in the longissimus dorsi of $\mathrm{Mstn}^{-/-}$Meishan pig also increased significantly compared with the wild-type pigs. These data show that the insulin signaling pathway is activated in $\mathrm{Mstn}^{-/}$Meishan pigs' skeletal muscle. Furthermore we isolated the primary myoblasts from wild-type and $\mathrm{Mstn}^{-1-}$ Meishan pigs. We first examined the InsR expression in wild-type primary myoblasts stimulated with different concentrations of insulin. Results showed that InsR expression was at the highest level at an insulin concentration of $0.5 \mu \mathrm{g} / \mathrm{mL}$ (Supplementary Figure 1). Thus, we did the following insulin stimulation experiments at an insulin concentration of $0.5 \mu \mathrm{g} / \mathrm{mL}$. Results showed the levels of InsR and IRS1 proteins,
A



D

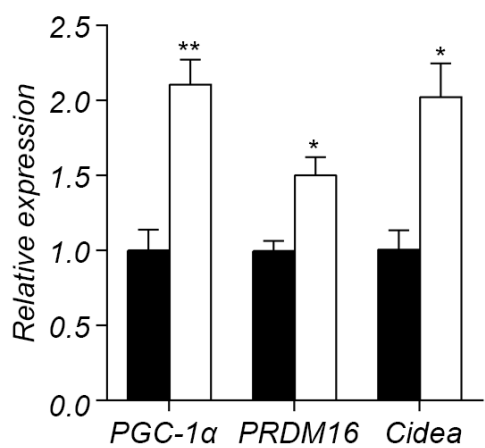

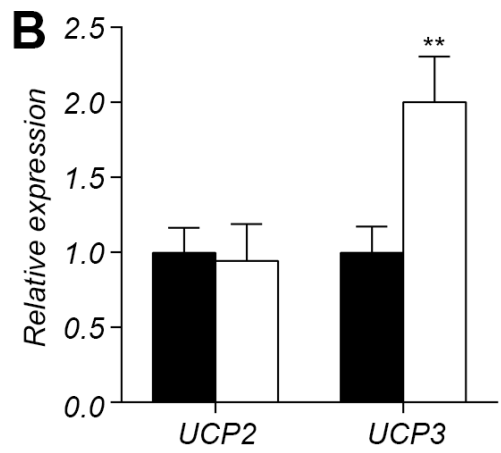

E

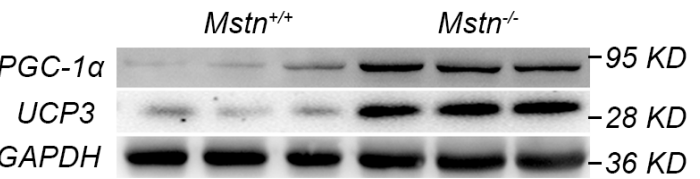

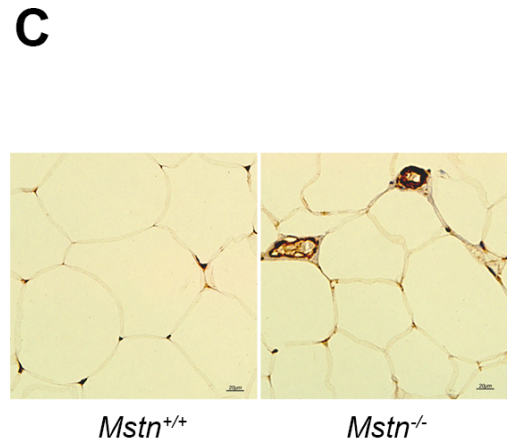

$\mathbf{F}$

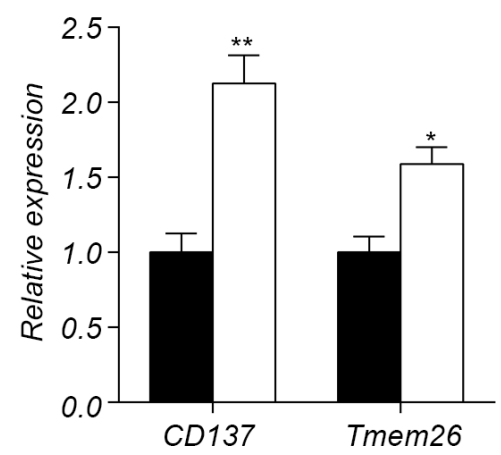

Figure 3: Browning of adipose fat tissue in $\mathrm{Mstn}^{-1-}$ pigs. (A) HE staining of dorsal subcutaneous adipose tissue between 6th and 7th ribs from 16-month old pigs. (B) RT-PCR analysis of UCP2 and UCP3 from dorsal subcutaneous fat from 16-month old pigs. Data are reported as mean $\pm \operatorname{SEM}(n=4) .{ }^{*} P<0.05, * * P<0.01, * * * P<0.001$. (C) UCP3 immunohistochemical staining of dorsal subcutaneous adipose tissue between the 6th and 7th ribs from 16-month old pigs. (D) RT-PCR analysis of PGC1- $\alpha$, PRDM16, Cidea in dorsal subcutaneous fat from 16-month old pigs. Data are reported as mean $\pm \operatorname{SEM}(n=4) . * P<0.05, * * P<0.01, * * * P<0.001$. (E) Western blot of PGC1- $\alpha$, UCP3 in dorsal subcutaneous fat. (F) RT-PCR analysis of CD137 and Tmem26 in dorsal subcutaneous fat. Data are reported as mean $\pm \operatorname{SEM}(n=4) .{ }^{*} P<0.05,{ }^{*} P<<0.01, * * * P<0.001$. Black bar: Sstn $^{+/+}$(wild-type) pigs; white bar: $M s t n^{-/-}$pigs. 
p-InsR and p-IRS1 proteins, along with the downstream proteins of the insulin signaling pathway such as p-Akt and GLUT4, all increased significantly in $\mathrm{Mstn}^{-/-}$Meishan porcine myoblasts (Figure 5C). These in vitro results, combined with the in vivo data described above, suggest that the inhibition of myostatin activity could increase the insulin sensitivity in skeletal muscle of Meishan pigs by activating insulin signaling pathway.

\section{Irisin-mediated regulation is not the only pathway for the activation of insulin signal in $\mathrm{Mstn}^{-1-}$ skeletal muscle}

Irisin is a new muscle factor that plays an important role in the regulation of insulin sensitivity. There had been reports that irisin level was significantly increased in Mstn ${ }^{-/}$mice skeletal muscle $[14,24]$. We further investigated the relationship between irisin and myostatin in the activation of insulin signaling pathway in skeletal muscle. Serum irisin level was significantly higher in the 4-monthold $\mathrm{Mstn}^{-/-}$Meishan pigs compared to the wild-type pigs (Figure 6A). Similarly, the expression and protein level of FNDC5, a precursor protein of irisin, also increased significantly in $\mathrm{Mstn}^{-/-}$skeletal muscle (Figure 6B, 6C). Therefore, we speculate that knockout of Mstn leads to an increase of irisin synthesis in skeletal muscle and thus results in the activation of insulin signaling pathway. We then investigated if there exists an alternative pathway in which irisin is not required for myostatin regulating insulin sensitivity in skeletal muscle. So FNDC5 interfering RNAs were first transfected in primary porcine myoblasts by a lentiviral vector. The lentiviral transfection efficiency was confirmed high (Supplementary Figure 2). As expected, FNDC5 expression at both transcriptional and translational levels was significantly reduced in FNDC5 SiRNA transfected myoblasts (Figure 6D, 6E). However, insulin stimulation experiments showed that the activation of insulin signal pathway in primary $\mathrm{Mstn}^{-/}$myoblasts was not abolished compared to the wild-type myoblasts (Figure 6F). These data indicate that the inhibition of irisin expression cannot abolish the activation of insulin signaling pathway by myostatin deletion in skeletal muscle, implying that irisin-mediated regulation is not the only pathway for the activation of insulin signal in $\mathrm{Mstn}^{--}$skeletal muscle.
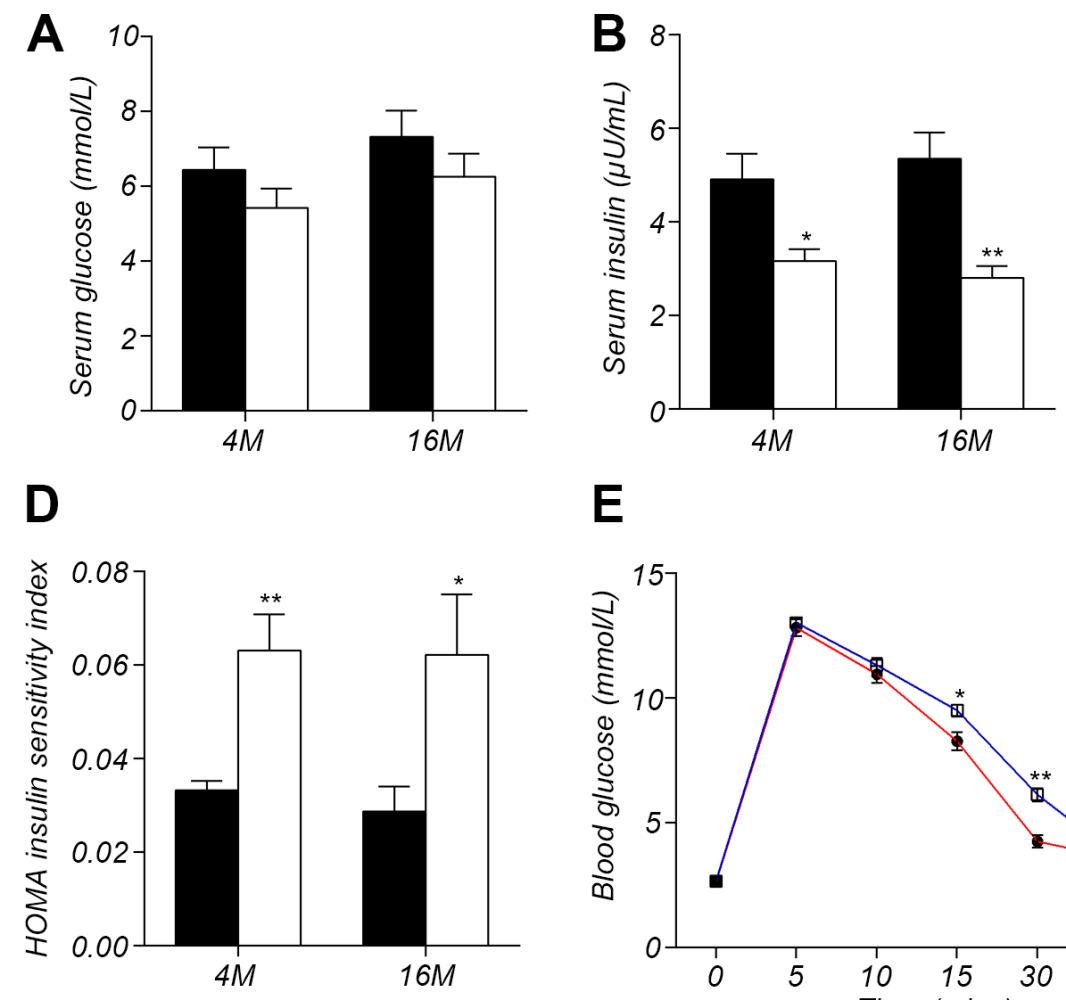

E

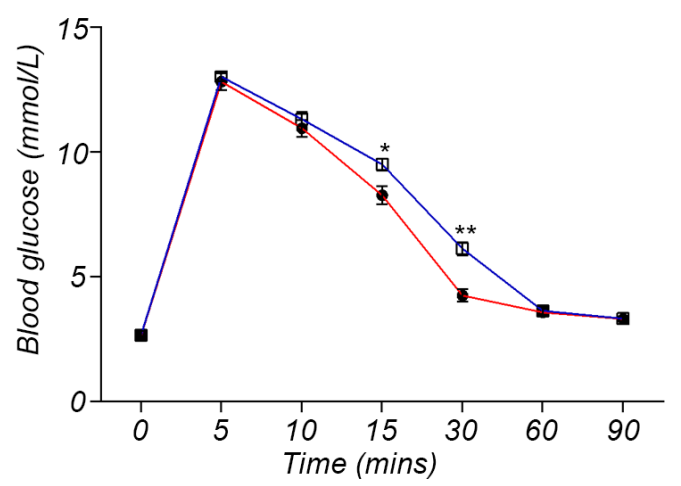

C

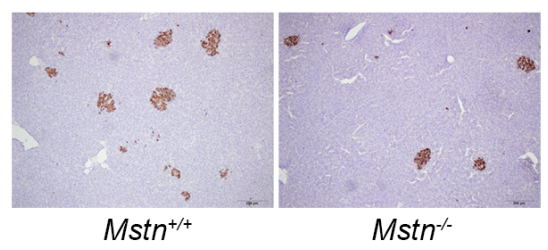

$\mathbf{F}$

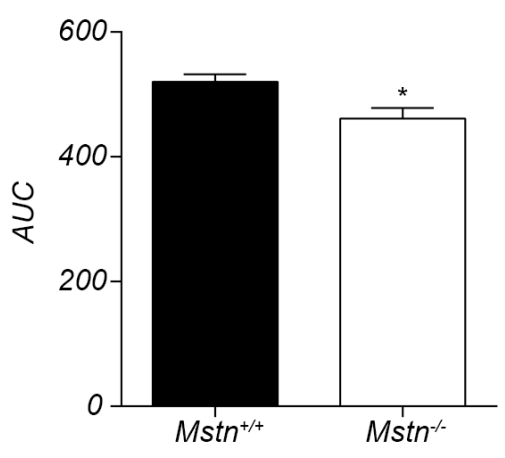

Figure 4: Myostatin deficiency induced increase in insulin sensitivity. (A) Serum glucose levels in 4-month old and 16-month old $\mathrm{Mst}^{+/+}$(wild-type) and $\mathrm{Mstn}^{-/-}$pigs. Data are reported as mean $\pm \operatorname{SEM}(n=4)$. (B) Serum insulin levels in 4-month old and 16-month old $\mathrm{Msth}^{+++}$(wild-type) and $\mathrm{Mstn}^{-/-}$pigs. Data are reported as mean $\pm \operatorname{SEM}(n=4) .{ }^{*} P<0.05, * * P<0.01, * * * P<0.001$. (C) Insulin immunohistochemical staining of porcine pancreas from 4-month old $\mathrm{Msth}^{+/+}$(wild-type) and $\mathrm{Mstn}^{-/-}$pigs. (D) Insulin sensitivity index in 4-month old and 16-month old $M s n^{+/+}$(wild-type) and $\mathrm{Mstn}^{-/-}$pigs. Data are reported as mean $\pm \operatorname{SEM}(n=4) . * P<0.05, * * P<0.01, * * * P$ $<0.001$. (E) Changes of blood glucose concentration at different time points during the glucose tolerance test. Data are reported as mean \pm $\operatorname{SEM}(n=4) . * P<0.05, * * P<0.01,{ }^{*} * * P<0.001$. The blue line is for wild-type pigs, and the red line is for $M s t n^{-/}$pigs, $(\mathbf{F})$ Calculated area under curve (AUC) for the glucose tolerance test. Data are reported as mean $\pm \operatorname{SEM}(n=4)$. $* P<0.05, * * P<0.01$, *** $P<0.001$. For A, B, D and F: Black bar: $M s t n^{+/+}$(wild-type) pigs; white bar: $M s t n^{-/-}$pigs. 


\section{DISCUSSION}

Animal models play an important role in human disease studies, and thus the selection of animals in this field is critical. Mouse is one of the most widely used animals due to its high reproduction rate, short life cycle, low cost, and easy experimental manipulation. However, mouse has its own disadvantages, which include huge differences in genome sequences and physiological structures between mouse and human. Thus, mouse is not an ideal animal to study human diseases. Recently, porcine genome sequences have been completed and published, and it was noted there is a very high similarity to human genome [25]. Additionally, pig has very similar physiological structure to human and high reproduction rate. These characteristics make pig an ideal model animal to study human diseases. Most importantly, pig has advantages in the research area of obesity and type 2 diabetes [29-31]. Like human, pigs eat all kinds of food including vegetables and meat. The sizes of fat cells as well as the fat distribution are very similar between pig and human. Both pig and human contain subcutaneous fat and visceral fat. The size, shape, and location of pancreas are also similar between pig and human. The size of the islets as well as the proportion and distribution of the different endocrine cell types is also very similar in pig and human. Porcine insulin differs from human insulin in only one amino acid at position 30 of the B-chain and has been used to treat diabetic patients. Pig and human also have similar metabolism system and cardiovascular system. Therefore, use of pig as an animal model is very important in studying human obesity and type 2 diabetes.

Myostatin is a muscular factor that negatively regulates the growth and development of skeletal muscle. In large animals such as bovines [5, 6], sheep [32], dogs [33], and humans [34], it has been found that natural mutations of myostatin result in skeletal muscle hypertrophy. Our results in this study demonstrated that
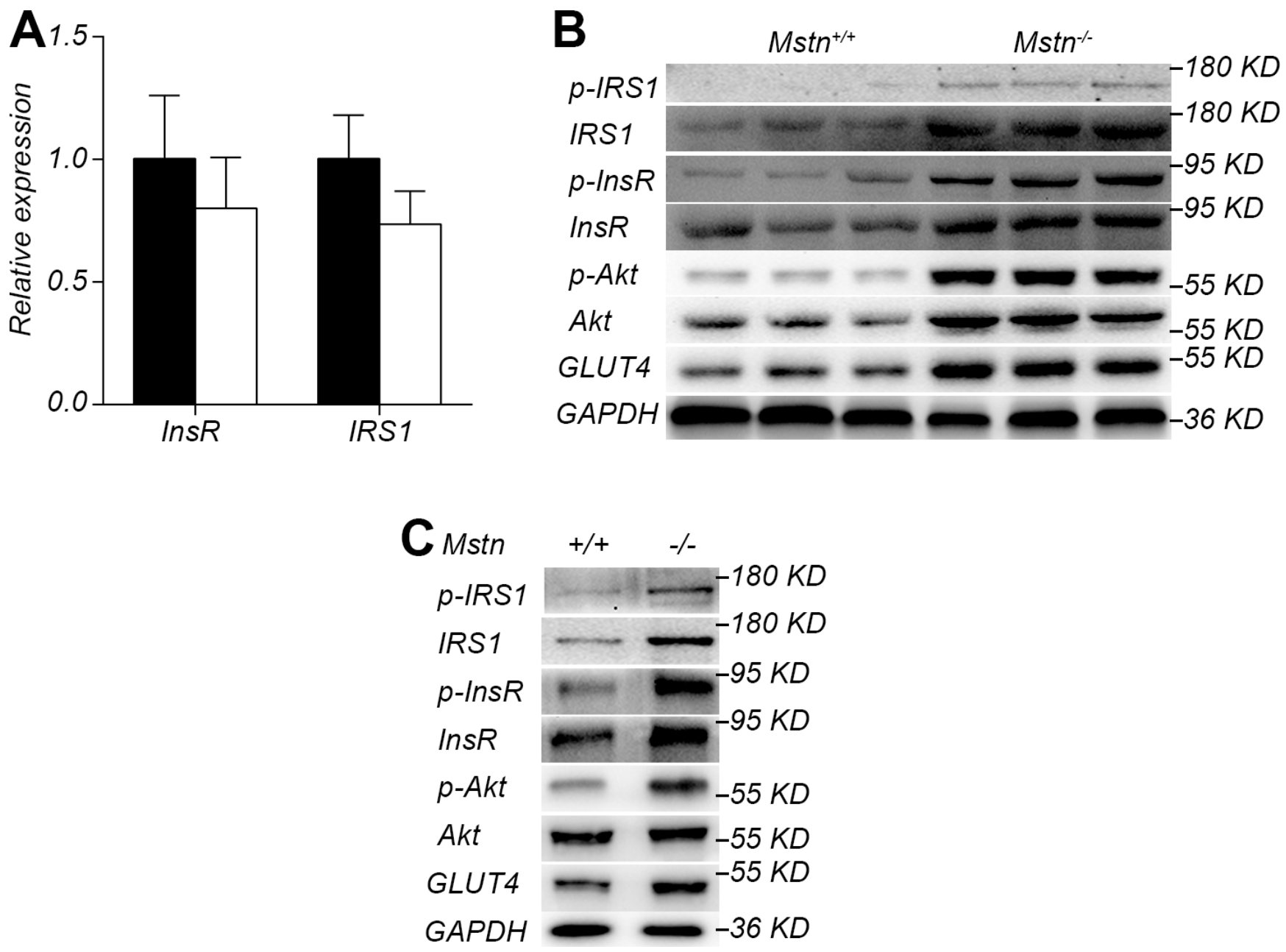

Figure 5: Activation of insulin signaling pathway by myostatin deficiency in skeletal muscle. (A) RT-PCR analysis of InsR and IRS1 in longissimus dorsi from 4-month old pigs. Data are reported as mean \pm SEM $(n=4)$. Black bar: Mstn $^{+++}($wild-type) pigs; white bar: $\mathrm{Mstn}^{-/}$pigs. (B) Western blot of insulin signaling pathway proteins IRS1, p-IRS1, InsR, p-InsR, Akt, p-Akt, and GLUT4 in longissimus dorsi from 4-month old pigs. (C) Western blot of insulin signaling pathway proteins IRS1, p-IRS1, InsR, p-InsR, Akt, p-Akt, and GLUT4 of myoblasts after stimulation by insulin. 
the skeletal muscle mass of $\mathrm{Mstn}^{-/}$Meishan pig was significantly higher than that of wild-type pigs at ages of 4 months and 16 months.

Adipose tissue is divided into white fat, brown fat, and beige fat $[35,36]$. The main function of white adipose tissue is to store energy, while the brown fat is to burn stored energy. Beige fat is a form of browning of white fat and has the function of brown fat. In mice, UCP1 is a brown fat marker gene, it can consume the stored energy in the form of heat. When myostatin activity is inhibited in mice, the expression of UCP1 in subcutaneous adipose tissue increased significantly, and the expression of PGC$1 \alpha$, PRDM16, and Cidea in white fat also increased significantly, which in turn induced more consumption of white fat [14]. It is known that porcine UCP1 gene is disrupted and cannot form active UCP1 protein [37]. UCP2 and UCP3 are also members of the uncoupling protein family, and they can also stimulate fat consumption $[38,39]$. J Jia at el [40] reported that feeding pigs with a low protein diet leads to an increase in thermogenesis and a significant increase in expression of UCP2 and UCP3 in skeletal muscle and fat tissue. In vivo, ATP synthesis increased significantly in primary skeletal muscle cells isolated from UCP3 knockout mice without any increase in TCA cycle flux rate, implying an increased degree of mitochondrial energy coupling [41]. All these observations indicate that UCP3 can generate heat by enhancing energy consumption. On the other hand, it was reported that no changes in UCP3 expression levels were observed when pigs were raised under extremely cold environment [42]. The energy expenditure of whole body in UCP3 knockout mice did not change [41]. In this study, the expression of UCP3 in the subcutaneous fat was significantly higher in $\mathrm{Mstn}^{-/-}$Meishan pigs compared to wild-type pigs. There are still disputes on the roles of porcine UCP3 in heat production and energy consumption, and therefore more research is required in this area.

Type 2 diabetes is a worldwide disease that posts a serious threat to human health. Insulin resistance is the leading cause of type 2 diabetes. So far, there was no study to report the relationship between myostatin and insulin sensitivity in large mammals. In this study, we observed that $\mathrm{Mstn}^{-/-}$Meishan pigs have significantly higher insulin sensitivity than wild-type pigs, which is consistent with
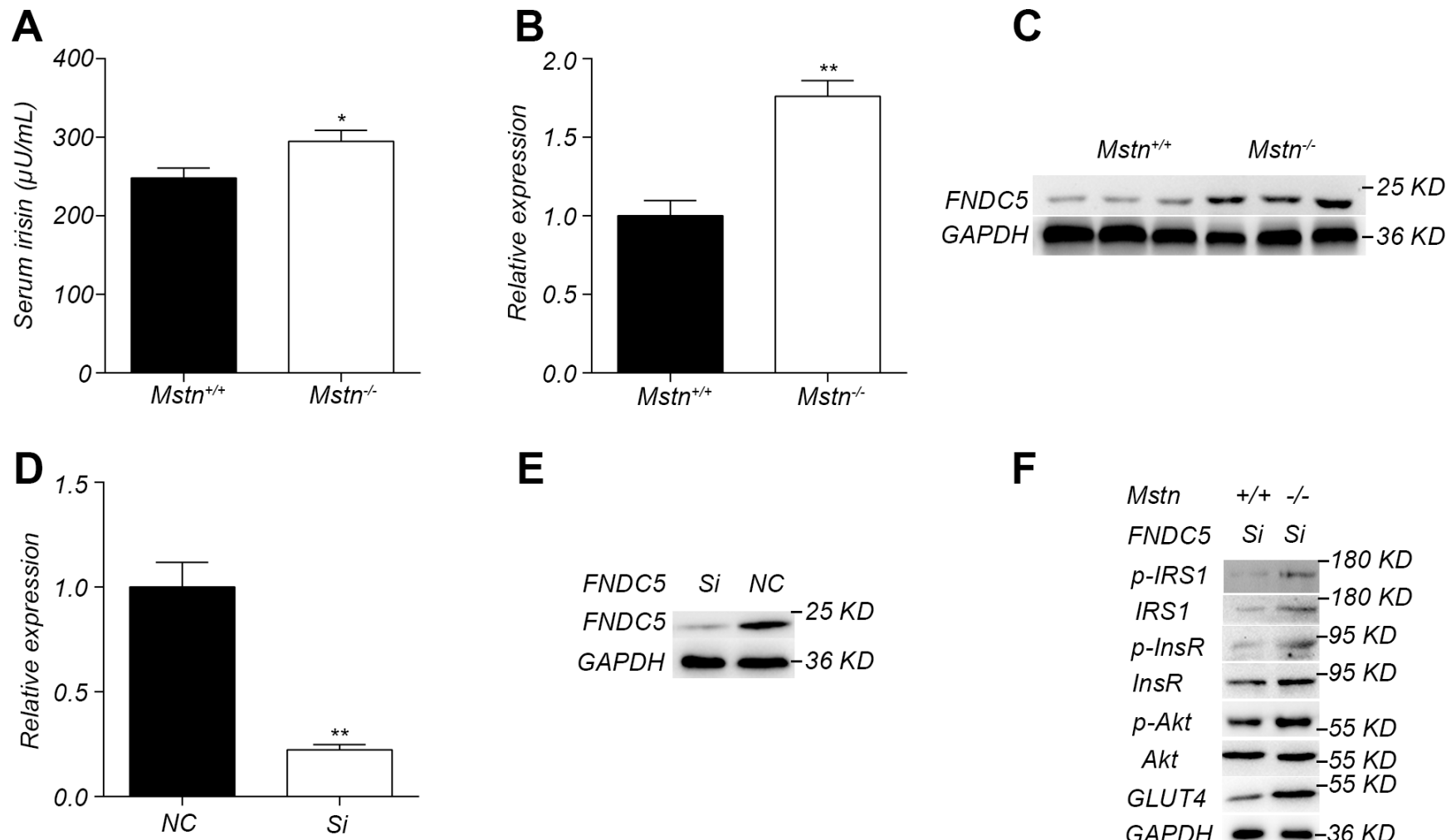

$\mathbf{E}$

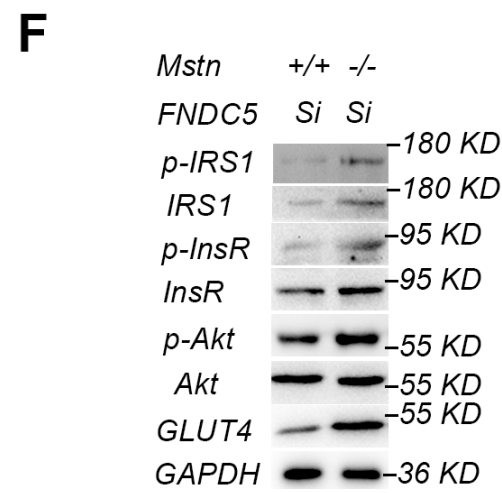

Figure 6: Irisin is not required for activation of insulin signaling pathway by myostatin deficiency. (A) Serum irisin levels in 4-month old $\mathrm{Mstn}^{+/+}$(wild-type) and $\mathrm{Mstn}^{-/}$pigs. Data are reported as mean $\pm \operatorname{SEM}(n=4) . * P<0.05, * * P<0.01, * * * P<0.001 .(\mathbf{B})$ RT-PCR analysis of FNDC5 in longissimus muscle from 4-month old $M s t n^{-1-}$ pigs. Data are reported as mean $\pm \operatorname{SEM}(n=4)$. ${ }^{*} P<0.05$, ${ }^{* *} P<0.01,{ }^{* * *} P<0.001$. (C) Western blot results of FNDC5 in longissimus dorsi from 4-month old $\mathrm{Mstn}^{+/+}$(wild-type) and Mstn ${ }^{-/-}$pigs. (D) RT-PCR analysis of FNDC5 in WT porcine myoblasts transfected with FNDC5 RNAi lentiviral vector ( $\mathrm{Si}$ ) and the control vector (NC). $* P<0.05,{ }^{*} P<0.01,{ }^{* * *} P<0.001$. (E) Western blot analysis of FNDC5 in WT porcine myoblasts transfected with RNAi lentiviral vector (Si) and the control vector (NC). (F) Western blot analysis of InsR, p-InsR, IRS1, p-IRS1, Akt, p-Akt, GLUT4, in wild type porcine and $M_{s t n^{-/}}$myoblasts transfected with RNAi lentiviral vector (Si). For A, B and D: Black bar: $M s t n^{+/+}$(wild-type) pigs; white bar: Mstn ${ }^{-/}$pigs. 
results reported in $\mathrm{Mstn}^{-/-}$mice $[13,23]$. There are a few reports on the molecular mechanism by which myostatin regulates insulin sensitivity. InsR and IRS1 are the key proteins of the insulin signal pathway, and inhibition of mouse InsR and IRS1 activity can lead to insulin resistance in mice [43-46]. Bonala et al. [8] have reported that myostatin can promote IRS1 ubiquitination and its degradation in mouse skeletal muscle, which in turn inhibit the activation of insulin signaling pathway, leading to insulin resistance. Our results showed that levels of InsR and IRS1 proteins in skeletal muscle from $\mathrm{Mstn}^{-/}$ Meishan pigs were significantly increased, which is the cause of activated insulin signaling. Our study is the first report that myostatin deficiency can activate the insulin signal and increase insulin sensitivity in large animals.

Irisin is an active secretory protein that is produced by the cleavage of its precursor protein FNDC5 [47]. Irisin protein is mainly synthesized in the skeletal muscle, and like myostatin, it is highly conserved among a variety of species. Irisin can significantly improve insulin sensitivity in mice $[31,48]$. Previous studies show that the increases in insulin sensitivity and expression of FNDC5 in skeletal muscle were observed in $\mathrm{Mstn}^{-/-}$mice [14, 24]. In our current study, we demonstrated that the activation of insulin signal pathway in primary $\mathrm{Mstn}^{-/}$myoblasts was not completely abolished by FNDC5 SiRNA, implying that irisin-mediated regulation is not the only pathway for the activation of insulin signal in $\mathrm{Mstn}^{-/-}$skeletal muscle. More studies are needed to further explore the molecular mechanism by which the insulin sensitivity is regulated by myostatin.

In summary, our results demonstrate that the increased browning process and fat consumption are the key reasons for a decreased fat deposition in $\mathrm{Mstn}^{-/}$Meishan pigs. The myostatin deficiency also resulted in a significant increase in insulin sensitivity and the activation of insulin signaling pathway in large animals. It is expected that inhibition of myostatin function can be an effective alternative approach in enhancing insulin sensitivity and thus for potential prevention and treatment of type 2 diabetes.

\section{MATERIALS AND METHODS}

\section{Animals}

$\mathrm{Mstn}^{-/-}$pigs were generated as previously described [26]. All experimental protocols related to animal work were approved by the Institute of Animal Sciences, Chinese Academy of Agricultural Sciences, Beijing, China. All experimental pigs, both wild-type $\left(M s t n^{+/+}\right)$and $\mathrm{Mstn}^{-/-}$, received adequate housing, feed (standard diet), access to water and bedding.

\section{Serum measurements}

The levels of serum glucose and triglyceride (TG) were determined with Biochemical analyzer (TBA-
120FR). Serum leptin was measured using the Porcine Leptin ELISA Kit (Elabscience, E-EL-P0063), and serum insulin concentration was measured with Porcine Insulin ELISA Kit (Lanpaibio, hj-C14701). Serum irisin level was determined by Irisin Competitive ELISA Kit (Biovision, K4761-100).

\section{Haematoxylin and eosin staining and immunohistochemistry}

Subcutaneous adipose tissue and pancreas were fixed in $4 \%$ paraformaldehyde at room temperature for $48 \mathrm{~h}$, followed by embedding in paraffin. Each fixed tissue was then sliced to $5 \mu \mathrm{m}$ in thickness to make slides, followed by haematoxylin and eosin (HE) staining and immunohistochemical staining. Immunohistochemistry was performed according to standard procedures to stain uncoupling protein 3 (UCP3) and insulin using anti-UCP3 antibody ((AB10985, Abcam) and anti-insulin antibody (AB195956, Abcam).

\section{RNA extraction, cDNA synthesis and real time PCR (RT-PCR)}

RNA extraction, cDNA synthesis and real time PCR were performed as previously described [26]. RT-PCR primers were shown in Supplementary Table 1. Porcine TATA-binding protein 1 (TBP1) gene was used as an internal control [49] to normalize the RT-PCR efficiency and to quantify the expression of the genes in wild-type and $\mathrm{Mstn}^{-/-}$pigs.

\section{Protein extraction and Western blot}

Total protein from the muscle and adipose tissue was extracted with T-PER Tissue Protein Extraction Reagent (Thermo, 78510), and total cellular protein was extracted with M-PER Mammalian Protein Extraction Reagent (Thermo, 78501). Protease inhibitor cocktail tablets (Roche, 04693159001) and phosphatase inhibitor cocktail tablets (Roche, 04906837001) were added to T-PER Tissue Protein Extraction Reagent and M-PER Mammalian Protein Extraction Reagent prior to use. Total protein concentration was determined using a Micro $\mathrm{BCA}^{\mathrm{TM}}$ Protein Assay Kit (Thermo, 23235). Each protein sample was loaded in equal amount and then separated by $10 \%$ SDS PAGE. Following transfer of protein from gel to NC membrane (Merck Millipore, HATF00010) and blocked with 5\% BSA (Amresco, 9048-46-8) for 2h, Western blot was performed using standard method for the following proteins with corresponding detection antibodies (in brackets): IRS1 [Cell Signal Technology (CST), 2825], phosphorylated IRS1 (p-IRS1) (CST, 2831), insulin receptor (InsR) (CST, 3025), p-InsR (CST, 3023), serine/ threonine kinase 1 (Akt) (CST, 9272), p-Akt (CST, 9271), facilitated glucose transporter 4 (GLUT4) (CST, 2213), 
PGC-1 $\alpha$ (Santa, sc-13067), UCP3 (Abcam, ab10985), fibronectin type III domain containing 5 (FNDC5) (Abcam, ab174833), anti-mouse secondary antibody (CST, 7076), anti-rabbit secondary antibody (CST, 7074). Glyceraldehyde-3-phosphate dehydrogenase (GAPDH) (CST, 2118) was used as an internal reference in Western blot. SuperSignal West Pico chemiluminescent substrate (Thermo, 34080) was used to develop color band.

\section{Glucose tolerance test}

$50 \%$ glucose $(1.2 \mathrm{ml} / \mathrm{kg}$ of body weight) was injected into the ear vein to each of the 4-month-old Meishan pigs. Level of blood glucose was measured at different time points after injection using a blood glucose meter (SANNUO).

\section{Isolation of primary skeletal myoblasts}

Newly born piglets were euthanized and soaked in $75 \%$ alcohol for $5 \mathrm{~min}$. The longissimus dorsi muscle was separated and cut into pieces, followed by adding $0.1 \%$ collagenase type I (GIBCO, 17100017) and incubation at $37^{\circ} \mathrm{C}$ for 2 hours. Then $0.25 \%$ trypsin was added and incubated for $5 \mathrm{~min}$ to release cells, followed by adding 20\% FBS (GIBCO, 10099-141), DMEM/F12 (Hyclone, $\mathrm{SH} 30023.01 \mathrm{~B}$ ), and 1\% penicillin-streptomycin to stop the digestion process. Cells were then filtered $(70 \mu \mathrm{m})$. The filtrate was centrifuged to remove supernatant, and the cell pellet was then resuspended in culture medium containing 20\% FBS, DMEM/F12, 1\% penicillin-streptomycin. Cells were then transferred into $60 \mathrm{~mm}$ dish, incubated at $37^{\circ} \mathrm{C}$ and $5 \% \mathrm{CO}_{2}$ for 2 hours, the supernatant containing myoblasts was then transferred into $35 \mathrm{~mm}$ dish, incubated at $37^{\circ} \mathrm{C}$ and $5 \% \mathrm{CO}_{2}$, and changed culture medium once every 2 days.

\section{Insulin stimulation}

Insulin stimulation experiments were performed as described by Bonala et al. (8) using the primary myoblasts at a cell density of 10000 cells $/ \mathrm{cm}^{2}$ in DMEM/F12 medium containing $20 \%$ FBS and $1 \%$ penicillin-streptomycin.

\section{Lentiviral-mediated transduction}

The FNDC5 interfering RNA sequence (GCGATGCACAACTTTGCAAGT) was designed by GenePharma. Vector construction and lentiviral packaging were also performed by GenePharma. The primary myoblasts were inoculated in T25 flask. When cell confluency reached 50\%, DMEM/F12 medium containing $20 \%$ FBS was added along with $10 \mu \mathrm{L}$ of virus stock and $5 \mu \mathrm{g} / \mathrm{mL}$ of Polybrene. Cells were then incubated at $37^{\circ} \mathrm{C}$ and $5 \% \mathrm{CO}_{2}$ for 24 hours. At $24 \mathrm{~h}$ hours and 48 hours, fresh DMEM/F12 medium containing 20\% FBS was replaced, respectively. Then DMEM/F12 medium containing 20\% FBS and $5 \mu \mathrm{g} / \mathrm{mL}$ of Puromycin was added. Cell culture was continued with fresh medium being changed every three days until stable expression of red fluorescent protein was observed.

\section{Data analysis}

All data were analyzed by using unpaired 2-tailed Student's $t$ tests $(P<0.05)$.

\section{Abbreviations}

Mstn: Myostatin; GDF8: Growth/differentiation factor 8; TGF $\beta$ : Transforming growth factor beta superfamily; WT: Wild-type; UCP: Uncoupling protein; PGC-1 $\alpha$ : Peroxisome proliferative activated receptor, gamma, coactivator 1 alpha; PRDM16: PR domain containing 16; Cidea: Cell death-inducing DNA fragmentation factor, alpha subunit-like effector A; CD137: Tumor necrosis factor receptor superfamily member 9; Tmem26: Transmembrane protein 26; IRS1: Insulin receptor substrate 1; p-IRS1: Phosphorylated insulin receptor substrate 1; ZFN: Zinc-fingers Nuclease; AUC: Area under curve; InsR: Insulin receptor; p-InsR: Phosphorylated insulin receptor; Akt: Serine/threonine kinase; p-Akt: Phosphorylated serine/threonine kinase; GLUT4: Facilitated glucose transporter member 4; HE staining: Haematoxylin and eosin staining; RT-PCR: Real time PCR; TBP1: TATA-binding protein 1; FBS: Fetal bovine serum; DMEM/F12: Dulbecco s Modified Eagle Media: Nutrient Mixture F-12; TCA: tricarboxylic acid.

\section{Authors' contributions}

C. C. conducted most experiments and performed data analysis. L. Q., S. J., and Y. S. conducted part of animal experiments. Q. W. and D. M. performed part of Western blot experiments. G. X. and B. L. did some RTPCR experiments. S. X. and T. G. did Haematoxylin and eosin staining and immunohistochemistry. Y. C., J. L., X. A., W. C., and K. L. designed this study. C. C. and W. C. wrote the manuscript.

\section{ACKNOWLEDGMENTS}

We thank the following: Dr. Jin-an Jiao for editing this manuscript; Mr Ke Jiang and Mr Hegang Li for care and management of pig farm; Drs. Shulin Yang, Yanfang Wang, Zhonglin Tang, Yulian Mou, and Hong Ao for their guidance and suggestions.

\section{CONFLICTS OF INTEREST}

The authors have no conflicts of interest to declare. 


\section{FUNDING}

This study was supported by National Program on Key Basic Research Project (2015CB943100), National Transgenic Project of China (2014ZX08006-003, 2016ZX08006-001) and The Agricultural Science And Technology Innovation Program (ASTIP-IAS05)

\section{REFERENCES}

1. McPherron AC, Lawler AM, Lee SJ. Regulation of skeletal muscle mass in mice by a new TGF-p superfamily member. Nature. 1997; 387:83-90.

2. Sharma M, Kambadur R, Matthews KG, Somers WG, Devlin GP, Conaglen JV, Fowke PJ, Bass JJ. Myostatin, a transforming growth factor- $\beta$ superfamily member, is expressed in heart muscle and is upregulated in cardiomyocytes after infarct. J Cell Physiol. 1999; 180:1-9.

3. Jiao J, Yuan T, Zhou Y, Xie W, Zhao Y, Zhao J, Ouyang $\mathrm{H}$, Pang D. Analysis of myostatin and its related factors in various porcine tissues. J Anim Sci. 2011; 89:3099-3106.

4. Lee SJ, McPherron AC. Regulation of myostatin activity and muscle growth. Proc Natl Acad Sci U S A. 2001; 98:9306-9311.

5 Grobet L, Martin LJ, Poncelet D, Pirottin D, Brouwers B, Riquet J, Schoeberlein A, Dunner S, Ménissier F, Massabanda J, Fries R, Hanset R, Georges M. A deletion in the bovine myostatin gene causes the double-muscled phenotype in cattle. Nat Genet. 1997; 17:71-74.

6. McPherron AC, Lee SJ. Double muscling in cattle due to mutations in the myostatin gene. Proc Natl Acad Sci U S A. 1997; 94:12457-12461.

7. Allen DL, Cleary AS, Speaker KJ, Lindsay SF, Uyenishi J, Reed JM, Madden MC, Mehan RS. Myostatin, activin receptor IIb, and follistatin-like-3 gene expression are altered in adipose tissue and skeletal muscle of obese mice. Am J Physiol Endocrinol Metab. 2008; 294:E918-E927.

8. Bonala S, Lokireddy S, McFarlane C, Patnam S, Sharma M, Kambadur R. Myostatin induces insulin resistance via Casitas B-lineage lymphoma b (Cblb)-mediated degradation of insulin receptor substrate 1 (IRS1) protein in response to high calorie diet intake. J Biol Chem. 2014; 289:7654-7670.

9. Hittel DS, Berggren JR, Shearer J, Boyle K, Houmard JA. Increased secretion and expression of myostatin in skeletal muscle from extremely obese women. Diabetes. 2009; 58:30-38.

10. Zhao B, Wall RJ, Yang J. Transgenic expression of myostatin propeptide prevents diet-induced obesity and insulin resistance. Biochem Biophys Res Commun. 2005; 337:248-255.

11. Lin J, Arnold HB, Della-Fera MA, Azain MJ, Hartzell DL, Baile CA. Myostatin knockout in mice increases myogenesis and decreases adipogenesis. Biochem Biophys Res Commun. 2002; 291:701-706.
12. McPherron AC, Lee SJ. Suppression of body fat accumulation in myostatin-deficient mice. J Clin Invest. 2002; 109:595-601.

13. Wilkes JJ, Lloyd DJ, Gekakis N. Loss-of-function mutation in myostatin reduces tumor necrosis factor $\alpha$ production and protects liver against obesity-induced insulin resistance. Diabetes. 2009; 58:1133-1143.

14. Shan T, Liang X, Bi P, Kuang S. Myostatin knockout drives browning of white adipose tissue through activating the AMPK-PGC1 $\alpha$-Fnde5 pathway in muscle. FASEB J. 2013; 27:1981-1989.

15. Zhang C, McFarlane C, Lokireddy S, Masuda S, Ge X, Gluckman PD, Sharma M, Kambadur R. Inhibition of myostatin protects against diet-induced obesity by enhancing fatty acid oxidation and promoting a brown adipose phenotype in mice. Diabetologia. 2012; 55:183-193.

16. DeFronzo RA, Tripathy D. Skeletal muscle insulin resistance is the primary defect in type 2 diabetes. Diabetes Care. 2009; 32:S157-S163.

17. Kahn S. The relative contributions of insulin resistance and beta-cell dysfunction to the pathophysiology of type 2 diabetes. Diabetologia. 2003; 46:3-19.

18. Mayerson AB, Hundal RS, Dufour S, Lebon V, Befroy D, Cline GW, Enocksson S, Inzucchi SE, Shulman GI, Petersen KF. The effects of rosiglitazone on insulin sensitivity, lipolysis, and hepatic and skeletal muscle triglyceride content in patients with type 2 diabetes. Diabetes. 2002; 51:797-802.

19. Guo T, Bond ND, Jou W, Gavrilova O, Portas J, McPherron AC. Myostatin inhibition prevents diabetes and hyperphagia in a mouse model of lipodystrophy. Diabetes. 2012; 61:2414-2423.

20. Guo T, Jou W, Chanturiya T, Portas J, Gavrilova O, McPherron AC. Myostatin inhibition in muscle, but not adipose tissue, decreases fat mass and improves insulin sensitivity. PloS One. 2009; 4:e4937.

21. Brandt C, Nielsen AR, Fischer CP, Hansen J, Pedersen BK, Plomgaard P. Plasma and muscle myostatin in relation to type 2 diabetes. PLoS One. 2012; 7:e37236.

22. Allen DL, Hittel DS, McPherron AC. Expression and function of myostatin in obesity, diabetes, and exercise adaptation. Med Sci Sports Exerc. 2011; 43:1828.

23. Zhang C, McFarlane C, Lokireddy S, Bonala S, Ge X, Masuda S, Gluckman PD, Sharma M, Kambadur R. Myostatin-deficient mice exhibit reduced insulin resistance through activating the AMP-activated protein kinase signalling pathway. Diabetologia. 2011; 54:1491-1501.

24. Dong J, Dong Y, Dong Y, Chen F, Mitch WE, Zhang L. Inhibition of myostatin in mice improves insulin sensitivity via irisin-mediated cross talk between muscle and adipose tissues. Int J Obes. 2016; 40:434-442.

25. Groenen MA, Archibald AL, Uenishi H, Tuggle CK, Takeuchi Y, Rothschild MF, Rogel-Gaillard C, Park C, Milan D, Megens HJ, Li S, Larkin DM, Kim H, et al. 
Analyses of pig genomes provide insight into porcine demography and evolution. Nature. 2012; 491:393-398.

26. Qian L, Tang M, Yang J, Wang Q, Cai C, Jiang S, Li H, Jiang K, Gao P, Ma D, Chen Y, An X, Li K, et al. Targeted mutations in myostatin by zinc-finger nucleases result in double-muscled phenotype in Meishan pigs. Sci Rep. 2015; 5:14435.

27. Frederich RC, Hamann A, Anderson S, Löllmann B, Lowell BB, Flier JS. Leptin levels reflect body lipid content in mice: evidence for diet-induced resistance to leptin action. Nat Med. 1995; 1:1311-1314.

28. Bartelt A, Bruns OT, Reimer R, Hohenberg H, Ittrich H, Peldschus K, Kaul MG, Tromsdorf UI, Weller H, Waurisch C, Eychmüller A, Gordts PL, Rinninger F, et al. Brown adipose tissue activity controls triglyceride clearance. Nat Med. 2011; 17:200-205.

29. Houpt KA, Houpt TR, Pond WG. The pig as a model for the study of obesity and of control of food intake: a review. Yale J Biol Med. 1979; 52:307.

30. Spurlock ME, Gabler NK. The development of porcine models of obesity and the metabolic syndrome. J Nutr. 2008; 138:397-402.

31. Wolf E, Braun-Reichhart C, Streckel E, Renner S. Genetically engineered pig models for diabetes research. Transgenic Res. 2014; 23:27-38.

32. Clop A, Marcq F, Takeda H, Pirottin D, Tordoir X, Bibé B, Bouix J, Caiment F, Elsen JM, Eychenne F, Larzul C, Laville E, Meish F, et al. A mutation creating a potential illegitimate microRNA target site in the myostatin gene affects muscularity in sheep. Nat Genet. 2006; 38:813-818.

33. Mosher DS, Quignon P, Bustamante CD, Sutter NB, Mellersh CS, Parker HG, Ostrander EA. A mutation in the myostatin gene increases muscle mass and enhances racing performance in heterozygote dogs. PLoS Genet. 2007; 3:e79.

34. Schuelke M, Wagner KR, Stolz LE, Hübner C, Riebel T, Kömen W, Braun T, Tobin JF, Lee SJ. Myostatin mutation associated with gross muscle hypertrophy in a child. N Engl J Med. 2004; 350:2682-2688.

35. Giralt M, Villarroya F. White, brown, beige/brite: different adipose cells for different functions? Endocrinology. 2013; 154:2992-3000.

36. Harms M, Seale P. Brown and beige fat: development, function and therapeutic potential. Nat Med. 2013; 19:1252-1263.

37. Berg F, Gustafson U, Andersson L. The uncoupling protein 1 gene (UCP1) is disrupted in the pig lineage: a genetic explanation for poor thermoregulation in piglets. PLoS Genet. 2006; 2:e129.

38. Bezaire V, Spriet LL, Campbell S, Sabet N, Gerrits M, Bonen A, Harper ME. Constitutive UCP3 overexpression at physiological levels increases mouse skeletal muscle capacity for fatty acid transport and oxidation. FASEB J. 2005; 19:977-979.
39. Damon M, Vincent A, Lombardi A, Herpin P. First evidence of uncoupling protein-2 (UCP-2) and-3 (UCP-3) gene expression in piglet skeletal muscle and adipose tissue. Gene. 2000; 246:133-141.

40. Jia J, Jois M, McDowell G. Tissue expression of uncoupling proteins in piglets given a low protein diet: a role for UCP2 and UCP3 in diet-induced thermogenesis. Animal Science. 2005; 81:283-287.

41. Cline GW, Vidal-Puig AJ, Dufour S, Cadman KS, Lowell BB, Shulman GI. In vivo effects of uncoupling protein-3 gene disruption on mitochondrial energy metabolism. J Biol Chem. 2001; 276:20240-20244.

42. Herpin P, Damon M, Le Dividich J. Development of thermoregulation and neonatal survival in pigs. Livest Prod Sci. 2002; 78:25-45.

43. Kulkarni RN, Brüning JC, Winnay JN, Postic C, Magnuson MA, Kahn CR. Tissue-specific knockout of the insulin receptor in pancreatic $\beta$ cells creates an insulin secretory defect similar to that in type 2 diabetes. Cell. 1999; 96:329-339.

44. Stefan N, Vozarova B, Funahashi T, Matsuzawa Y, Weyer C, Lindsay RS, Youngren JF, Havel PJ, Pratley RE, Bogardus C, Tataranni PA. Plasma adiponectin concentration is associated with skeletal muscle insulin receptor tyrosine phosphorylation, and low plasma concentration precedes a decrease in whole-body insulin sensitivity in humans. Diabetes. 2002; 51:1884-1888.

45. Yu C, Chen Y, Cline GW, Zhang D, Zong H, Wang Y, Bergeron R, Kim JK, Cushman SW, Cooney GJ, Atcheson B, White MF, Kraegen EW, et al. Mechanism by which fatty acids inhibit insulin activation of insulin receptor substrate-1 (IRS-1)-associated phosphatidylinositol 3-kinase activity in muscle. J Biol Chem. 2002; 277:50230-50236.

46. Aguirre V, Werner ED, Giraud J, Lee YH, Shoelson SE, White MF. Phosphorylation of Ser307 in insulin receptor substrate-1 blocks interactions with the insulin receptor and inhibits insulin action. J Biol Chem. 2002; 277:1531-1537.

47. Boström P, Wu J, Jedrychowski MP, Korde A, Ye L, Lo JC, Rasbach KA, Boström EA, Choi JH, Long JZ, Kajimura S, Zingaretti MC, Vind BF, et al. A PGC1- $\alpha$-dependent myokine that drives brown-fat-like development of white fat and thermogenesis. Nature. 2012; 481:463-468.

48. Staiger H, Böhm A, Scheler M, Berti L, Machann J, Schick F, Machicao F, Fritsche A, Stefan N, Weigert C, Krook A, Häring HU, de Angelis $\mathrm{MH}$. Common genetic variation in the human FNDC5 locus, encoding the novel muscle-derived 'browning' factor irisin, determines insulin sensitivity. PloS One. 2013; 8:e61903.

49. Nygard, AB, Jørgensen CB, Cirera S, Fredholm M. Selection of reference genes for gene expression studies in pig tissues using SYBR green qPCR. BMC Mol Biol. 2007; 8:1. 